\title{
Climate Change and the Brazilian Broiler Meat Production Chain
}

\author{
Robert A. Waker and Irenilza A. Nääs \\ Paulista University, São Paulo, Brazil \\ bobwaker@gmail.com
}

\begin{abstract}
Brazil is one of the world largest exporters of broiler meat, and this sector is highly vulnerable to the estimate of climate change. The objective of this theoretical research is to present the importance of climate change, considering the effect of global warming, in the broiler meat supply chain, as well as the main guidelines for the analysis of the variables related to the production cost of the poultry farms. The theoretical concepts of the broiler chicken production process chain and the dynamics of climate change have been studied. Moreover, by mapping the productive network with their respective inputs and outputs, applying the cause/effect diagram it was possible to display the primary variables that might contribute to the operational performance of the chain. The result of the study pointed out the most important components that contribute to cost generation in the broiler meat production chain, considering the global temperature variations.
\end{abstract}

Keywords: Meat market $\cdot$ Climate change $\cdot$ Broiler meat supply chain

\section{Introduction}

A vast increase in demand for animal production is expected in the next decades, due to the world population growth. It is estimated that the human population by 2050 will reach 9.6 billion, with most of the increase expected to take place in developing countries. It is estimated that $85 \%$ of world population will live in regions of developing countries [1]. Chicken meat is one of the most important meat in the global market since it is easy to produce and it does not require much use of land. Global production is expected to increase by $2 \%$ to a record 89.3 million tons by all key international players. After overcoming China and becoming the second largest producer in 2015, Brazil will continue to expand due to the stable feed costs and an increase in exports [2]. Considering the meat production in Brazil, chicken meat is the first in production, followed by beef and pork, in this order [3].

A global climate change will cause changes in the local climate and will impact on agricultural and livestock production, in the two levels respectively. The main conclusions of the Intergovernmental Panel on Climate Change (IPCC), the Fifth Assessment Report (AR5) were [4]:

- The warming of the climate system is unequivocal; 
- Anthropogenic warming is likely to continue for centuries due to the timescales associated with climate processes;

- The heating of the air at the surface in the 21st Century, at the best estimate, will vary from $1.1^{\circ} \mathrm{C}$ to $2.9^{\circ} \mathrm{C}$ for an "optimistic scenario" and $2.4^{\circ} \mathrm{C}$ to $6.4^{\circ} \mathrm{C}$ for a "worst case scenario".

Authors believe [5] that animal production systems based on grazing and mixed farming systems will be most affected by global warming, when compared to industrial systems, such as poultry farms. This is due to the negative effect of lower rainfall generating more droughts and affecting crops and pasture growth, besides the direct effects of high temperatures and direct solar radiation on animals.

The challenge is how to achieve a better balance, increased production or productivity per unit, and at the same time improving the sustainability of the poultry industry. The broiler meat supply chain typically has the following configuration: breeder - poultry farm - slaughterhouse - end consumer [6]. Fig. 1 shows the supply chain in the present study, where the actors were identified, as well as its roles, and the flow of products within the chain $[7,8]$. The flow of

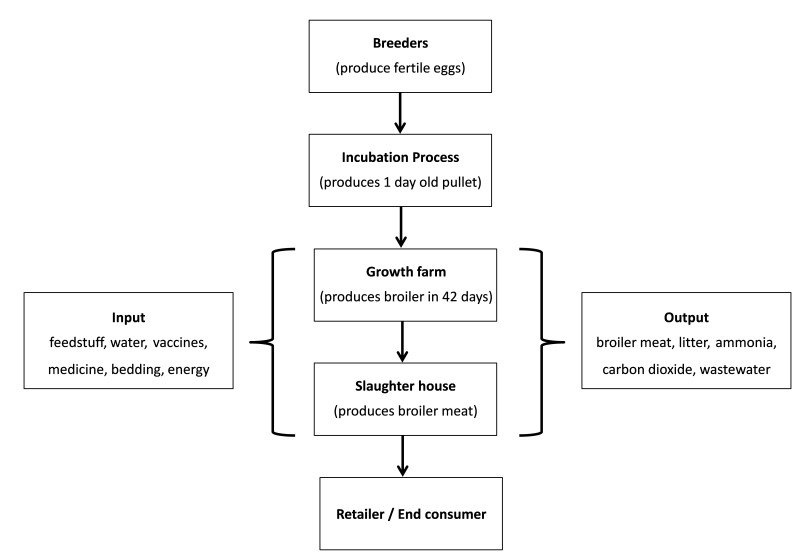

Fig. 1. Broiler meat production chain flow. Source: Adapted from [7].

product/capital/information starts from the producer of broiler matrices at the beginning of the chain and flows to the consumer market at the end of the chain. This flow is bidirectional, and in one direction we have the products of each actor and in the opposite direction, we have feedback with information plus the capital payback of its operations. Each player can generate sub-products, such as raw material for fertilizers or materials for disposal. The animal production facilities are large generators of ammonia, nitrous oxide, methane and carbon dioxide in the atmosphere and contribute to the acidification of soil and global warming [9]. 
The dynamic of broiler activity is directly related to the technology employed which generates substantial benefits in productivity, through improved feed conversion rates, increased nutritional gains, genetic research, and especially by automation of farms and slaughterhouses, and better production management [7]. Brazilian chicken meat is sold both in the domestic and international markets, as carcass and/or parts with aggregated value [8]. The poultry production chain is considered an industrial system. These industrial systems through the processing plants are the most important source of pig and poultry meat. Today this meat industry provide to the world' consumers nearly $70 \%$ of chicken, $60 \%$ of eggs and $55 \%$ of pork [5].

In the present scenario, the organizations that compose the meat supply chain have considerable challenges to manage their business units. There are goals and results to be achieved in a high competitive market. For these administrations, there are several factors to being known and mastered to obtain the expected results.

The objective of this research is to describe the possible effects of climate change in the evolution of broiler meat production chain. This paper presents the main system components that will be affected by climate change derived from global warming.

\section{Methodology}

Initially, secondary data were obtained with the objective of increase the necessary knowledge of issues such as climate change; chicken production chain and production processes. Many different reference sources were used, such as books and scientific articles, which provided the theoretical basis for the current study. In sequence, we used the cause/effect diagram, which is an analysis tool, to compile a list of components that may vary due to climate change.

The main issues on the influence of climate change on rearing broilers are: how this production system is dependent on the weather, which components of this system will be affected, and what can we do to deal with these effects. The weather dependency level acts directly on the animal (performance; health; well-being; nutrition and reproduction), and it can be affected by the weather conditions in a short or medium period [10].

Data were organized, and the productive chain was studied considering only two actors: (1) the farms that produce broilers, and (2) the slaughterhouses that produce carcasses and other cuts. The inputs and outputs of this subsystem were considered as (1) inputs to produce broilers (goods and capital), and (2) the output of the meat production destined for the domestic market and exports (goods and capital) [8]. Fig. 2 shows the studied actors with their respective inputs and outputs. The cause/effect diagram is an analysis tool used to display the relationship between a result of a process (effect) and factors (causes) that may have caused the considered result. For the current study, the variables were identified through literature review. The brainstorming technique was used to 


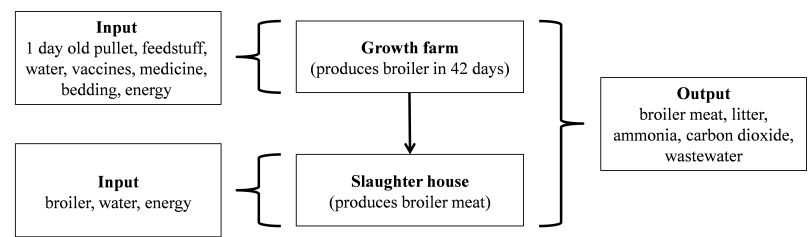

Fig. 2. Analyzed actors of the broiler meat production chain with their inputs and outputs

determine the possible accountable factors for the performance of the production cost.

Due to a large number of variables involved, both in direct or indirect climatic effects that configure the productive system, the variables affected were simplified. An accurate study would require much knowledge and data in many disciplines, and it would be time-consuming. Therefore, the present study provides an overview of some relevant effects of global warming on the production of poultry and the dynamic components involved.

\section{Results and Discussion}

Climate change through global warming can dramatically affect the performance of the broilers production system, impacting the worldwide production [5]. The input components that undergo variations due to climate changes in the evaluated production system are shown in Fig. 3 through the cause/effect diagram. A high-temperature environment can compromise the reproductive efficiency of

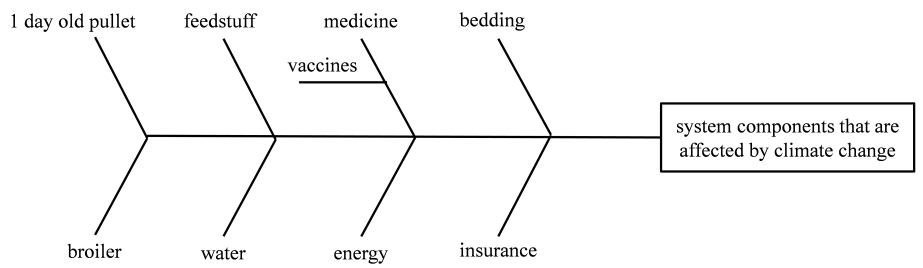

Fig. 3. Cause/effect diagram

livestock production in both sexes and thus adversely affect the milk, meat and egg production. Exposure to high ambient temperature decreases fertility in broilers, rabbits and horses [5]. Temperatures greater than $30^{\circ} \mathrm{C}$ are sufficient to generate heat stress to poultry. Especially in hot regions, heat stress is a great concern for the poultry industry due to the poor growth and performance and high mortality rates [11]. High ambient temperatures in the rearing area may lead to high mortality in broilers. Other effects are the reduction in feed intake, 
low body and carcass weight, low protein content in the carcass, and a little caloric muscle content [5]. It is important that the environment is maintained at $32^{\circ} \mathrm{C}$ for the one-day-old pullet, and is reduced by one degree Celsius every life day until chicks reach ambient temperature [12].

Under global warming, water will be the main common weak point in livestock production systems. The water consumption by the birds is higher at higher temperatures [12]. The animals exposed to hot environments drink an amount of water 2 to 3 times more than those in thermally neutral conditions [5]. A study on the management of water use in a poultry slaughterhouse showed a more intelligent use should be applied in poultry production and processing [11]. The study refers to the procedures for dry cleaning, control over the amount of water utilized in a sector by sector basis, better disposal of blood residues, water automation and changes in the configuration system of the treatment wastewater plant.

Agriculture is the most vulnerable economic sector considering climate change, especially in developing countries. The two most important crops in the broiler feedstuff composition are corn and soybeans, respectively [12]. The feedstuff can be considered as a primary variable responsible for the cost of the broiler production system. Three variables must be evaluated to estimate the relationship between the production of corn and soybeans and climatic variations, which are the temperature, precipitation, and solar radiation [13]. In theory, the standard broiler producer, which is a rational farmer, take the production decisions based on, among other factors, the prices set by the market, to maximize net returns of crop production. The farmer can also make adaptations to climate change, adjusting cropping systems and using irrigation water in warmer seasons [13].

Manipulation of animal diet can be a practical way to limit the impact of the production on the environment by controlling the amount and composition of the produced manure and greenhouse gas emissions associated with this, as well as redefine the diet for a change in cost and availability of feed. Variations in the animal diet can affect the level of nitrogen, phosphorus and amount of excreta without penalizing animal health, welfare or performance [9]. The reduction in crude protein content in the poultry diet is also possible. It is important that the most suitable standard amino acid for each species of poultry is achieved by the addition of supplements. Ammonia reductions have been reported up to $50 \%$ when the crude protein content of the diets was reduced this way. For example, the decrease in crude protein content in laying rations of $30 \mathrm{~g} / \mathrm{kg}$ at constant lysine content will increase feed costs by about $16 \%$ [14].

The effects of climate change on the health of livestock have not been studied in depth. The acclimatization of the animals to face the thermal challenges results in reduced feed intake and changes in many physiological functions that are linked to decreased health and the change of productive and reproductive efficiency have been studied [5]. As an indirect impact on the animals, there is the influence of climate on microbial populations, distribution of vector-borne diseases, small host resistance to infectious agents, shortages of food and water, and food-borne diseases. At first, some used vaccines should not be changed, but 
according to [6], several studies have evaluated the relationship between thermal stress and immune responses in cattle, chickens and pigs. That is, with a lower immune response the probability to use a larger amount of medicine is inevitable.

The air purification systems of the facilities are used to reduce $\mathrm{NH}_{3}$ emissions, especially from pigs and broilers. The houses are mostly closed with forced ventilation. Forced ventilation also aims to control the room temperature to a more suitable thermal comfort for the birds [9]. Depending on the latitude of which the farm is located, there are different levels of electricity consumption for cooling or heating the place where the birds are. The air treatment can also remove fine dust and odor. For fattening livestock farms (chicken, turkey, duck) the main techniques for better production performance are (1) reducing loss of water from the system of the poultry using nozzles instead of bell drinkers, (2) treating the exhaust air, and (3) drying the manure by using forced air in order to reduce the emission of $\mathrm{NH}_{3}$ around $40 \%$ to $60 \%$. For farms that use bedding, waste management is as important as keeping the surface as dry as possible $[9,11]$.

The use of techniques to adjust the air temperature of poultry farms for a thermal neutral comfort for the animals, causes higher power consumption and thus aggravates global warming and increases the overall costs of animal production [5]. Research should continue to develop new techniques for cooling systems, such as thermal insulation; focusing more, in techniques that require less energy expenditure. The cost of the energy used is one of the crucial factors in the financial performance of farms and slaughterhouses.

Risk management requires using insurance to minimize potential losses regarding a particular event. A variety of different instruments exist, including protections directly attached to weather (the insured are paid in response to "trigger events" such as abnormal rainfall, for example) [10].

Inevitably, the reasons to resist implementing technology to protect specifically the environment of animal production activity will vary greatly depending on the local situation in which the actors are. The cost is an obvious problem, and it would be fair to say that few producers will invest in additional technologies that bring little benefit to them in the absence of regulatory pressure from the government [9].

\section{Conclusions}

Probably the effects of global warming on water availability may force the broilers production sector to establish a new priority in producing animal products that need less water (for feeding, cleaning, etc.).

Determine whether a particular farm or slaughterhouse meets environmental standards, or require investment in one or more areas is more a regulatory issue than a scientific question. The production response to meet food demand has to take place, not only in facing climate change, but should also consider the increase in world population as an additional challenge. Scientific research can help the broiler production chain in the battle against climate change. All scientists 
who work with animals should seek collaboration with colleagues from other disciplines (agronomists, meteorologists, engineers, economists, among others) to optimize the operating performance of the chain.

The raised components will have an enormous impact on small or large production systems. A better understanding of these probable impacts will be vital to determine and select strategic alternatives that may help the actors of the production chain to increase its financial performance, improve food security and sustain its natural resource base in the future.

\section{References}

1. UNDP (ed.): No. 2015 in Human development report, United Nations Development Programme, New York, NY (2015)

2. USDA: Livestock and Poultry: World Markets and Trade. Tech. rep., United States Department of Agriculture, Office of Global Analysis (2015)

3. ABPA.: Relatório Anual UBABEF 2015. Tech. rep., Associação Brasileira de Proteína Animal, São Paulo (2015)

4. Intergovernmental Panel on Climate Change (ed.): Climate Change 2014: Synthesis Report. Intergovernmental Panel on Climate Change, Geneva, Switzerland (2015)

5. Nardone, A., Ronchi, B., Lacetera, N., Ranieri, M., Bernabucci, U.: Effects of Climate Changes on Animal Production and Sustainability of Livestock Systems. Livestock Science 130(1-3), 57-69 (2010)

6. Bukhori, I.B., Widodo, K.H., Ismoyowati, D.: Evaluation of Poultry Supply Chain Performance in XYZ Slaughtering House Yogyakarta Using SCOR and AHP Method. Agriculture and Agricultural Science Procedia 3, 221-225 (2015)

7. Oliveira, D., Nããs, I.d.A., Mollo Neto, M., Canuto, S., Waker, R., Vendrametto, O.: Issues of Sustainability on the Brazilian Broiler Meat Production Chain. Conference Proceedings of the International Conference on Advances in Production Management Systems. (2012)

8. Nääs, I., Mollo Neto, M., Canuto, S., Waker, R., Oliveira, D., Vendrametto, O.: Brazilian Chicken Meat Production Chain: A 10-year Overview. Revista Brasileira de Ciência Avícola 17(1), 87-94 (2015)

9. Loyon, L., Burton, C., Misselbrook, T., Webb, J., Philippe, F., Aguilar, M., Doreau, M., Hassouna, M., Veldkamp, T., Dourmad, J., Bonmati, A., Grimm, E., Sommer, S.: Best available technology for European livestock farms: Availability, effectiveness and uptake. Journal of Environmental Management 166, 1-11 (2016)

10. Thornton, P.K., Herrero, M.: Climate Change Adaptation in Mixed Crop-livestock Systems in Developing Countries. Global Food Security 3(2), 99-107 (2014)

11. Skunca, D., Tomasevic, I., Djekic, I.: Environmental Performance of the Poultry Meat Chain - LCA Approach. Procedia Food Science 5, 258-261 (2015)

12. Figueiredo, E.A.P.d., Schmidt, G.S., Avila, V.S.d., Jaenisch, a.R.F., Paiva, D.P.d.: Recomendações Técnicas para a Produção, Abate, Processamento e Comercialização de Frangos de Corte Coloniais. Sistemas de Produção 3, 1678-8850 (2007)

13. Chen, S., Chen, X., Xu, J.: Impacts of Climate Change on Agriculture: Evidence from China. Journal of Environmental Economics and Management 76, 105-124 (2016)

14. Veldkamp, T., Star, L., Van Der Klis, J., Van Harn, J.: Reduction of Ammonia Emission from Poultry Houses by Nutrition. Tech. rep., Wageningen UR Livestock Research, Netherlands (2012) 